\title{
Practical use of the UIC 406 capacity leaflet by including timetable tools in the investigations
}

\author{
A. Landex ${ }^{1}$, A. H. Kaas ${ }^{2}$, B. Schittenhelm ${ }^{3}$ \& J. Schneider-Tilli ${ }^{4}$ \\ ${ }^{1}$ Centre for Traffic and Transport, \\ Technical University of Denmark, Denmark \\ ${ }^{2}$ Atkins Denmark A/S, Denmark \\ ${ }^{3}$ Rail Net Denmark, Denmark \\ ${ }^{4}$ The National Rail Authority, Denmark
}

\begin{abstract}
This paper describes the relatively new UIC 406 method for calculating capacity consumption on railway lines. The UIC 406 method is an easy and effective way of calculating the capacity consumption, but it is possible to expound the UIC 406 method in different ways which can lead to different capacity consumptions. This paper describes how the UIC 406 method is expounded in Denmark.

The paper describes the importance of choosing the right length of the line sections examined and how line sections with multiple track sections are examined. Furthermore, the possibility of using idle capacity to run more trains is examined.

At the end of the paper a method to examine the expected capacity utilization of future timetables is presented. The method is based on the plan of operation instead of the exact (known) timetable.

Keywords: capacity, capacity analysis, compressed timetable graphs, timetable, UIC 406, railway, railway operation.
\end{abstract}

\section{Introduction}

The UIC 406 leaflet from year 2004 [9] describes a simple, but fast and effective way to evaluate the capacity utilization of railway lines. The capacity analyses carried out during the last years using the UIC 406 method have been presented in a number of papers (e.g. [3] and [10]). However, it is possible to expound the 
UIC 406 method in different ways which can lead to different results. In spite of that fact, hardly any analyses of the differences have been carried out.

This paper describes the UIC 406 method (cf. section 3) and a number of analyses carried out to generate a Danish consensus of expounding the UIC 406 leaflet for capacity analysis. A number of different analyses on relevant Danish railway lines have been carried out including:

- The length of the railway section examined (cf. section 4)

- The allowance of changing tracks on railway lines with multiple track sections (cf. section 5)

- The possibility of using idle capacity to run more trains (cf. section 6)

- The possibility of using the plan of operation instead of the exact timetable (cf. section 7)

At the end of the paper some conclusions and perspectives of the UIC 406 method are listed (in section 8).

\section{Definitions}

This paper uses terminology usually used in the railway literature. However, since the terminology differs from country to country, an overview of the terminology used in this paper is provided in Table 1.

Table 1: $\quad$ Short description of terminology.

\begin{tabular}{|l|l|}
\hline Term & Explanation \\
\hline $\begin{array}{l}\text { Block occupation } \\
\text { time }\end{array}$ & $\begin{array}{l}\text { The time a block section (the length of track between } \\
\text { two block signals, cab signals or both) is occupied by a } \\
\text { train }\end{array}$ \\
\hline Buffer time & $\begin{array}{l}\text { The time difference between actual headway and } \\
\text { minimum allowable headway }\end{array}$ \\
\hline Headway distance & $\begin{array}{l}\text { The distance between the front ends of two } \\
\text { consecutive trains moving along the same track in the } \\
\text { same direction. The minimum headway distance is the } \\
\text { shortest possible distance at a certain travel speed } \\
\text { allowed by the signalling and/or safety system }\end{array}$ \\
\hline Headway time & $\begin{array}{l}\text { The time interval between two trains or the (time) } \\
\text { spacing of trains or the time interval between the } \\
\text { passing of the front ends of two consecutive (vehicles } \\
\text { or) trains moving along the same (lane or) track in the } \\
\text { same direction }\end{array}$ \\
\hline $\begin{array}{l}\text { Running time } \\
\text { supplement }\end{array}$ & $\begin{array}{l}\text { The difference between the planned running time and } \\
\text { the minimum running time }\end{array}$ \\
\hline
\end{tabular}

Some of the terms described in Table 1 are further illustrated in Figure 1. 


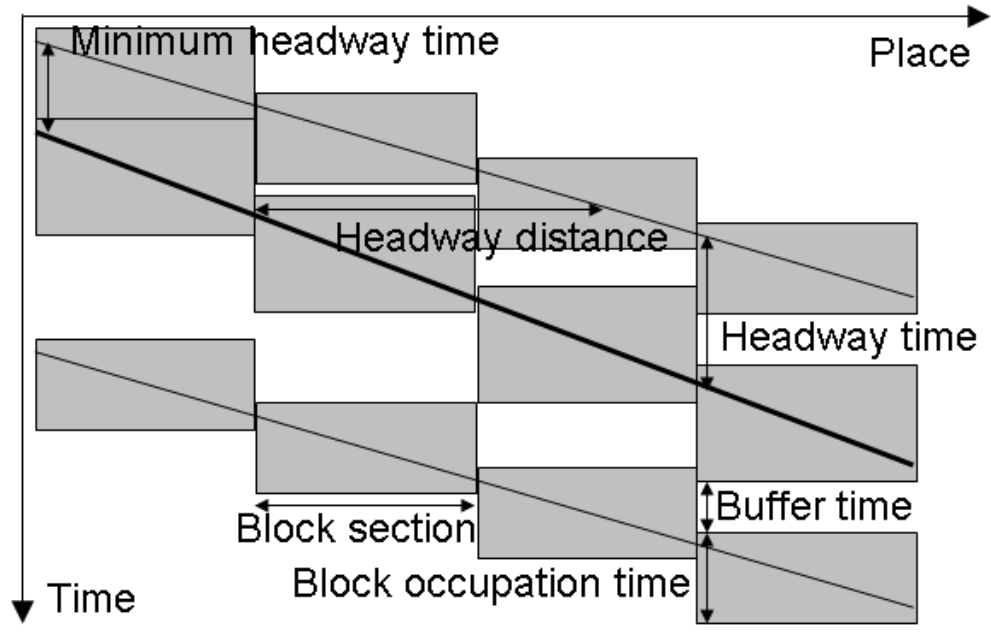

Figure 1: $\quad$ Time definitions [7].

\section{The UIC 406 method}

A detailed description of the UIC 406 method for capacity calculation is given in [9]. However, a brief description of the UIC 406 method will be given here.

Capacity consumption on railway lines depends on both the infrastructure and the timetable. Therefore, the capacity calculation according to the UIC 406 method is based on an actual timetable.

Timetables are created for the entire network and not only the line or line section which is of interest according to the capacity analysis. This means that the timetable in the analysis area depends on the infrastructure and timetable outside the analysis area - the so-called network effects [1]2]. These so-called network effects are not taken into account in the capacity analysis, why the capacity used according to the UIC 406 method will be less than or equal to the actual capacity consumption.

The capacity calculation is based on the compression of timetable graphs on a defined line or line section. All single train paths are pushed together to the minimum headway time, so that no buffer times are left. The compression of the timetable graph has to be done with respect to the train order and the running times. This means that neither the running times, running time supplement, dwell times or block occupation times are allowed to be changed. Furthermore, only scheduled overtakings and scheduled crossings are allowed.

\section{The length of the railway section examined}

The capacity calculation is based on compression of timetable graphs on defined line sections as described in section 3 and in [9]. However, the timetable graphs can only be compressed as the critical block section allows. Therefore, it is 
important not to split the railway line into several smaller line sections uncritically, while the critical block section thereby might be excluded from the analysis.

The critical block section is the block section which is occupied for the longest time. For homogenous traffic the critical block section can be anywhere on the line, but normally the critical block section is located close to a station or halt due to the reduced speed [4]. For inhomogeneous traffic like the Coast Line (Kystbanen) in Denmark (cf. Figure 2) the critical block section is usually located where the fast trains catch up with the slower trains.

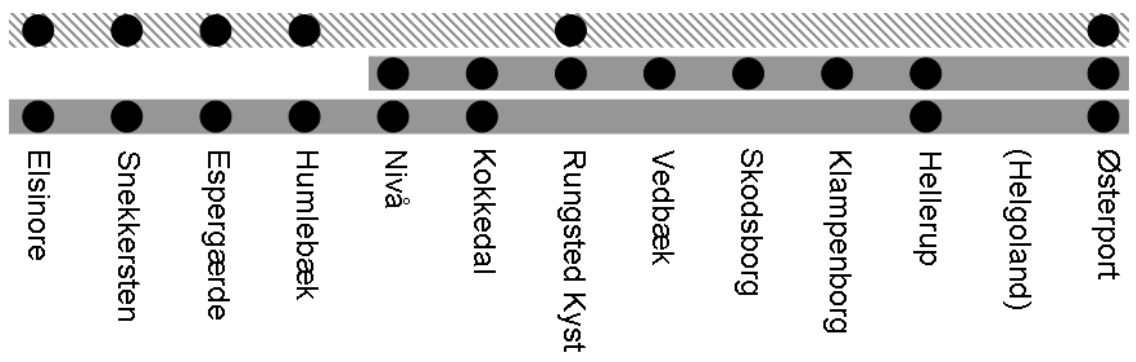

Figure 2: Train stopping patterns for the Coast Line in the rush hours $(20 \mathrm{~min}$ service).

On the railway line between Copenhagen (Østerport) and Elsinore - the Coast Line - there is an inhomogeneous traffic (cf. Figure 2). The critical block sections or bottlenecks on the Coast Line are at Nivå and Hellerup where the trains catch up with each other. To analyse the capacity utilization of the bottlenecks it was decided to use the UIC 406 method, cf. Figure 3.

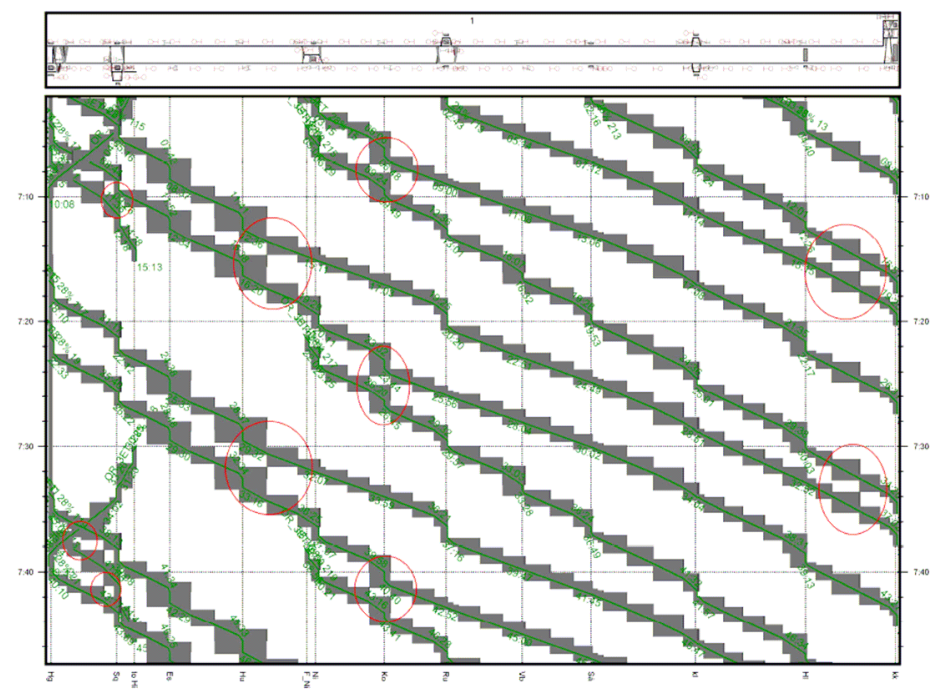

Figure 3: Timetable graph compression according to the UIC 406 method. 
To test the UIC 406 method, 3 different line sections were examined. The 3 line sections were Kokkedal-Humlebæk, Helgoland-Klampenborg and the whole line section between Helgoland and Elsinore. The results from the analysis show a big difference in the capacity utilization at the bottlenecks, cf. Table 2.

Table 2: Capacity utilization on the Coast Line according to the UIC 406 method during the rush hour.

\begin{tabular}{|l|c|c|}
\hline & \multicolumn{2}{|c|}{ Capacity utilization in \% } \\
\hline & Nivå & Hellerup \\
\hline Short line sections & 49 & 46 \\
\hline All line sections & 94 & 84 \\
\hline Difference & 45 & 38 \\
\hline
\end{tabular}

Table 2 shows that the short line sections give much lower capacity consumption than the whole line section. The low capacity utilization at the short line sections can lead to the wrong conclusion that there is room enough to run more trains. However, running more trains will make it more or less impossible to keep a good punctuality (see section 6).

Based on the results from the Coast Line it can be concluded that it is important to examine the whole railway line and not just a smaller area when capacity analyses are carried out. However, it is not always possible to examine a whole railway line due to the analysis resources. Therefore, the effort has to focus on the analysis examining where the railway line can be divided into smaller line sections. Furthermore, it is necessary to be careful when comparing capacity utilizations and only compare relatively.

\section{Changing between tracks at stations and at lines with more than two tracks}

Compressing timetable graphs according to the UIC 406 method can lead to discussions on line sections with quadruple tracks. An example from the Capacity analysis of the line between Copenhagen and Ringsted [8] illustrates the problems. A freight train is running from Ringsted to the freight terminal at Høje Taastrup. Simultaneously with the freight train passing Roskilde, a regional train from Lejre towards Copenhagen leaves Roskilde, cf. Figure 4.

When compressing the timetable graphs there will inevitably be a conflict because the trains have to change use of track at either Roskilde or Høje Taastrup station. The capacity consumption of the line section depends on which train runs on which track between Roskilde and Høje Taastrup and thereby where the conflict between the trains occurs, cf. Figure 4.

Using the UIC 406 method on line sections with quadruple tracks it has (in Denmark) been decided to give priority to the track occupations of the actual timetable or a timetable with a minimum number of conflicts. In the Danish method it is only allowed to move one or more trains from one track to another if there is an unequal utilization of the tracks. Not until then is the consideration of passenger preferences taken into account. The passenger preferences are only 
taken into account late in the process, since the UIC 406 method is used for capacity analysis.

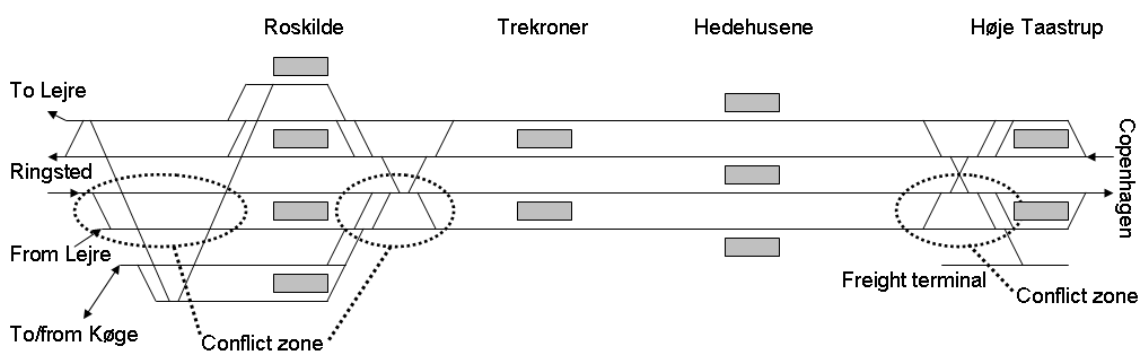

Figure 4: Conceptual track layout for the line section Høje Taastrup Roskilde.

Quadruple track sections are usually used for fast trains to overtake slower trains. In the Danish way of using the UIC 406 method for capacity analysis, it has been decided that the order of the trains has to be the same as in the reference timetable (cf. Figure 5 a) in both ends of the line section when compressing the timetable graph (cf. Figure $5 \mathrm{~b}$ ). The train order has to be the same in both ends of the line section even though the timetable graphs can be compacted more if the trains change the order (cf. Figure $5 \mathrm{c}$ ). The train order has to be the same due to the limitations of the infrastructure and timetable outside the analysis area - the so-called network effects [1]2].
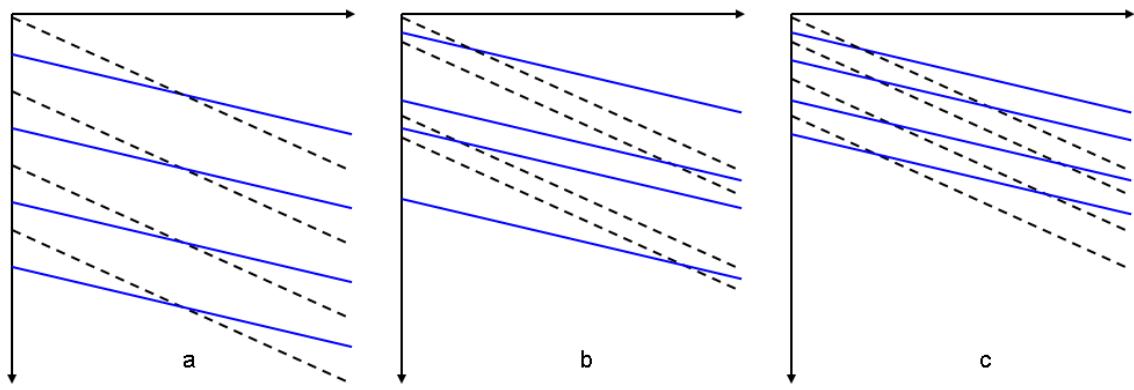

Figure 5: Timetable compression on quadruple track.

\section{The possibility of using idle capacity to run more trains}

The UIC 406 method describes the amount of capacity used on a certain railway line. However, not used capacity can not always be used to run more trains. In Figure 6 it is shown how the buffer times between the trains can give idle capacity by compressing the timetable graph and thereby make it possible to run an extra train. 


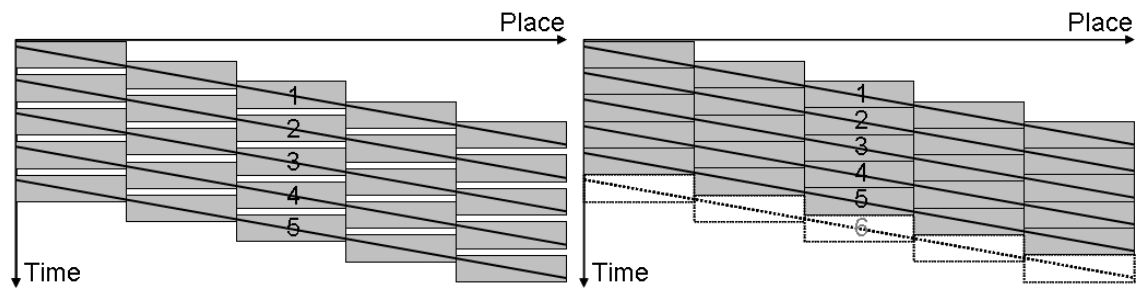

Figure 6: $\quad$ Usage of idle capacity.

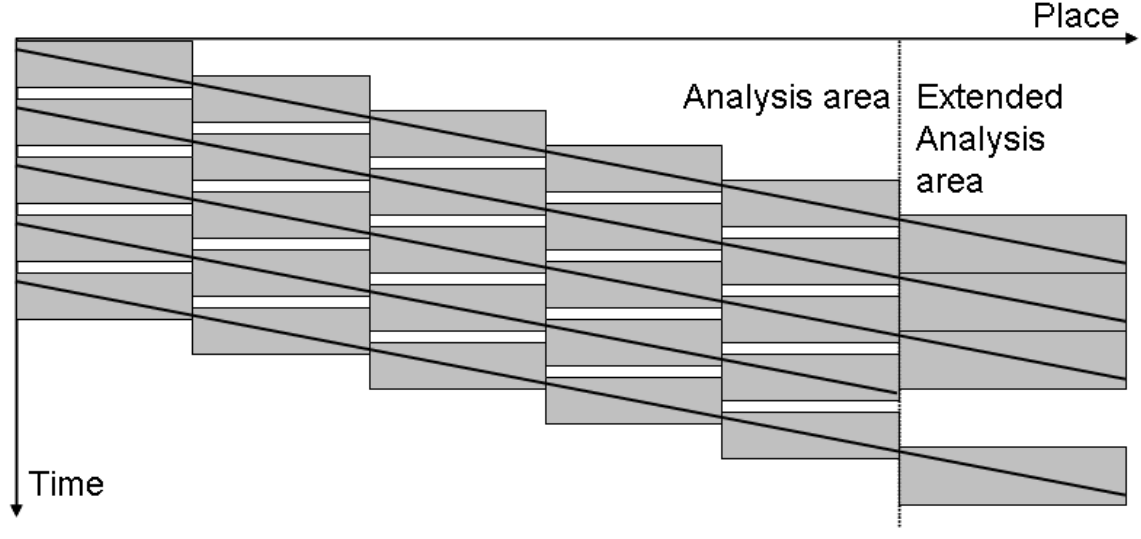

Figure 7: $\quad$ Limited possibility of compressing timetable graph.

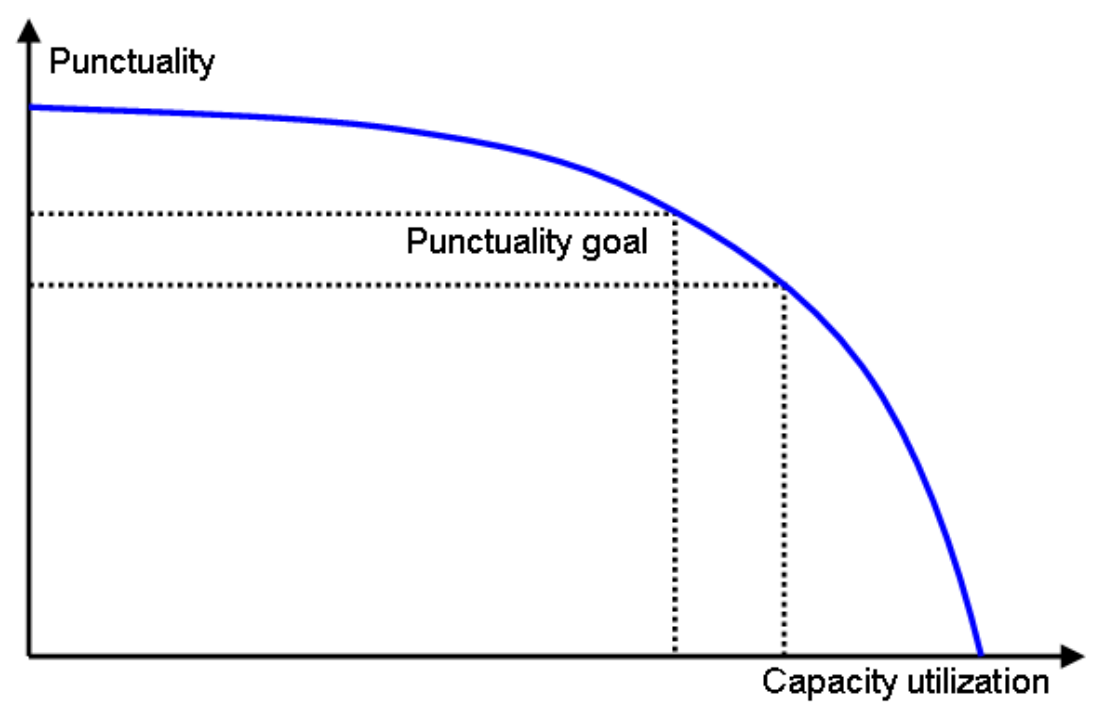

Figure 8: The coherence between punctuality and capacity utilization (based on [5]). 
It is, however, not always possible or wise to use the idle capacity or buffer time to run more trains. If there is a larger block section outside the evaluation area, it is not possible to run an extra train due to the lack of capacity outside the evaluation area, cf. Figure 7.

Even though it is possible to run more trains, it is not always wise to do so because it will reduce the buffer times. By reducing the buffer times, the risks of secondary delays are increased. Furthermore, the dispatching of the trains is made more difficult due to more trains in the system. Everything considered, the idle capacity can not always be used to run more trains. A weighing of the punctuality of the trains and the capacity utilization has to be done, so that the punctuality will not drop below a certain limit, cf. Figure 8.

\section{The possibility of using the plan of operation instead of the exact timetable}

It is difficult to analyse the capacity of a railway line which has not yet been built since the timetable for the opening year is unknown. Furthermore, the timetable can be changed over time. Therefore, examining the capacity utilization based on the plan of operation instead of the final timetable for the opening year is preferred. Since the capacity utilization is influenced by the order of the trains, it is necessary to make some assumptions of the train order or use methods used for successive calculation.

Using successive calculation, the average capacity utilization can be calculated as a weighted average of one (or more) likely value(s), the maximum value and the minimum value as shown in eqn (1):

$$
\text { Average }=\frac{\text { MinValue }+(3 \cdot \text { ActualValue })+\text { MaxValue }}{5} .
$$

The minimum value (MinValue) and the maximum value (MaxValue) of a plan of operation can be found by arranging the trains, so that the trains utilize as little or much capacity as possible, cf. Figure 9.
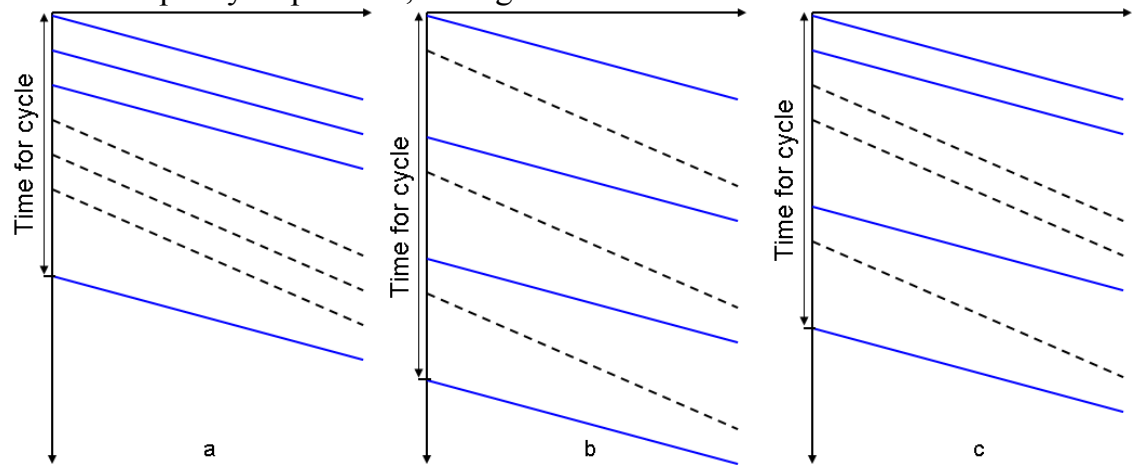

Figure 9: $\quad$ Plan of operation utilizing as little (a), as much (b) capacity as possible and an "actual" capacity consumption (c). 
Beside the values for the minimum and maximum capacity utilization it is also necessary to calculate 3 actual values for the capacity utilization, cf. eqn (1). This is due to the fact that the infrastructure outside the section of examination can limit the number of ways the trains can be ordered.

\section{Conclusion and perspectives}

The analysis has shown that the capacity utilization on railway lines is very responsive to the network examined. Therefore, the capacity utilization should only be compared relatively. In Denmark it has not yet been decided where to split the railway lines into smaller line sections - this work still remains to be done.

When there is a quadruple track available, it has been decided that the track occupations of the actual timetable should be used. If there is no actual timetable the timetable with the minimum number of conflicts should be examined instead. It is furthermore only allowed to move a train from one track to another if there is an unequal utilization of the tracks. The conditions for passengers transferring to e.g. busses are not taken into account.

Even though the capacity analysis shows that it is possible to run more trains in the section analysed, it is not always possible. The analysed line section can be too short to see that it is not possible to run more trains (e.g. due to capacity restrictions outside the analysis area) - the so-called network effects.

All the analyses have been carried out in the timetable and simulation software RailSys, but can also be carried out in the timetabling system STRAX/TPS which is used by the Danish railway agencies [6]. The result of the analysis is a common Danish method to evaluate the capacity utilization of railway lines in Denmark.

\section{References}

[1] Hansen, S., Landex, A. \& A.H. Kaas, The Network effects of Railway Investments, Proc. of the $10^{\text {th }}$ International Conference on Computers in Railways, eds. J. Allan, C.A. Brebbia, A.F. Rumsey, G. Sciutto, S. Sone \& C.J. Goodman, 2006

[2] Hansen, S., Large Transport Infrastructure Investments and their Strategic Impacts with a Special Focus on Enterprises, PhD. thesis at Centre for Traffic and Transport, Technical University of Denmark, 2004 (in Danish).

[3] Höllmüller, J. \& Klahn, V., Implementation of the UIC 406 capacity calculation at Austrian railways (ÖBB). Proc. of the $1^{\text {st }}$ International Seminar on Railway Operations Modelling and Analysis, eds. I.A. Hansen, F.M.Dekking, R.M.P. Goverde, B. Hindergott, L.E. Meester, The Netherlands, 2005

[4] Kaas, A. H., Methods to calculate capacity of railways, PhD. thesis at Department of Planning, Technical University of Denmark, 1998 (in Danish). 
[5] Kaas, A. H., Punctuality model for railways. Proc. of the $7^{\text {th }}$ International Conference on Computers in Railways, eds. J. Allan, R. J. Hill, C. A. Brebbia, G. Sciutto \& S. Sone, pp. 853-860, 2000

[6] Kaas, A. H. \& Goossmann, R., Implementation of the Timetable Planning System STRAX/TPS in Denmark. Proc. of the $9^{\text {th }}$ International Conference on Computers in railways, eds. J. Allan, C.A. Brebbia, R.J. Hill, G. Sciutto \& S. Sone, pp. 93-102, 2004

[7] Landex, A. \& Kaas, A. H., Planning the most suitable travel speed for high frequency railway lines. Proc. Of the $1^{\text {st }}$ International Seminar on Railway Operations Modelling and Analysis, eds. I.A. Hansen, F.M. Dekking, R.M.P. Goverde, B. Hindergott, L.E. Meester, The Netherlands, 2005

[8] Strategic analysis of Copenhagen-Ringsted - Comparing solutions for extending the railway capacity; The Danish Rail Authority, October 2005, Online. $\quad$ http://www.trafikstyrelsen.dk/graphics/SynkronLibrary/Trafikstyrelsen/Jernbane/Strategi/strategi beslutningsgrundlag_.p df (in Danish).

[9] UIC leaflet 406, Capacity, 2004, UIC International Union of Railways, France

[10] Wahlborg, M., Banverket experience of capacity calculations according to the UIC capacity leaflet. Proc. of the $9^{\text {th }}$ International Conference on Computers in railways, eds. C.A.- J. Allan, C.A. Brebbia, R.J. Hill, G. Sciutto \& S. Sone, pp. 665-673, 2004 